\title{
LA CONCEPCIÓN DE UN PROYECTO DE VALORIZACIÓN SOCIAL DEL PATRIMONIO ARQUEOLÓGICO. EL PLAN DE TOQUES COMO REFERENTE
}

\author{
POR \\ MATILDE GONZÁLEZ MÉNDEZ \\ Universidad de Santiago de Compostela \\ Grupo de Investigación en Arqueologia del Paisaje
}

\begin{abstract}
Todo este ambiente tiene, sin embargo, un aspecto bueno. Demuestra que en torno al saher prehistórico hay interés popular, sensacionalismo periodistico, manipulación politica, explotación turistica... Que conste que, en resumen, todo exto me parece positivo.
\end{abstract}

C. Alonso det Real.

\section{RESUMEN}

Utilizando como pretexto la realización de un proyecto para la rentabilización del patrimonio arqueológico del ayuntamiento de Toques ( La Coruña), se comentan las posibilidades que desde el actual marco legislativo y social se ofrecen para el diseño y puesta en práctica de estrategias de rentabilización y divulgación del patrimonio cultural y se discuten los criterios y carencias existentes a la hora de distinguir los bienes y elementos que serán objeto de actuaciones de este tipo. De otra parte, se describe la estrategia concreta que, con planteamientos basados en una linea de investigación arqueológica especifica (la Arqueología del Paisaje), hemos seguido en la elaboración del mencionado proyecto de rentabilización patrimonial del ayuntamiento de Toques.

\section{SUMMARY}

Using the setting up of a project for the social exploitation of the archaeological heritage of the borough of Toques (La Coruña) as a pretext, several comments arise concerning the available possibilities for the design and implementation of various strategies that, from within the current legislative and social framework, provide for the explotation and circulation of cultural heritage. Also criteria and shortcomings that exist at the time of identifying goods and elements that will be object of this type of activity are discussed.

Furthermore, a specific strategy is described that, with attitudes firmly based along a specific line of Archaeological research (Landscape Archaeology), we have followed with the creation of the aforementioned project for the explotation of the heritage of the borough of Toques.

\section{PRELUDIO: DE LA INVESTIGACIÓN A LA RENTABILIZACIÓN DEL PATRIMONIO ARQUEOLÓGICO}

El problema es el siguiente, ¿cómo es posible instrumentalizar una puesta en valor del patrimonio arqueológico? y ¿cómo es posible fundamentar esta puesta en valor en una estrategia concreta de investigación como es la Arqueología del Paisaje?

Estas cuestiones, en torno a cuya resolución gira el argumento fundamental de este trabajo, tratarán de ser satisfechas a través de la descripción, sintéti$\mathrm{ca}$, de los pasos seguidos en la elaboración de un proyecto de recuperación arqueológica realizado para el ayuntamiento de Toques, provincia de La Coruña ${ }^{1}$.

\footnotetext{
' Quiero agradecer a mis compañeros de trabajo en la sierra de $O$ Bocelo y ayuntamiento de Toques, asi como a los del grupo de trabajo en Arqueologia del Paisaje, el apoyo recibido en la elaboración del trabajo del que se nutre este artículo. También debo reconocer a M." Jesús Tallón y Faustino Infante los comentarios y sugerencias que han permitido mejorar este texto. Muchas de las ideas en él recogidas fueron definiéndose a lo largo de las discusiones y conversaciones mantenidas con Felipe Criado mientras compartimos el trabajo de redacción del mencionado proyecto, simbiosis desigual en la que he salido ganando. La parte gráfica ha sido delineada por Anxo Rodriguez Paz $y$, complementariamente, por Pilar Prieto e Ignacio Senin.
} 


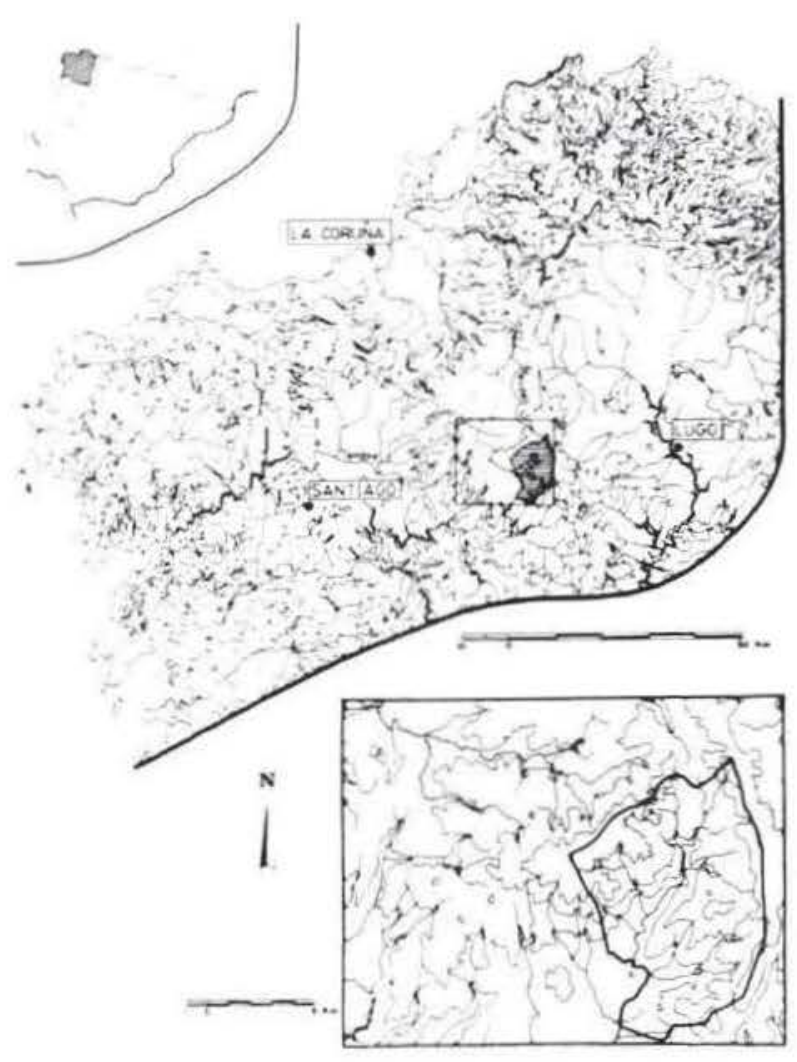

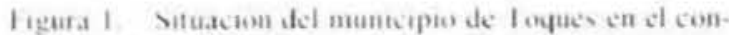
junto de Gialicia y de la peninsula thèrica.

Como preámbulo a esta descripción, conviene hacer dos precisiones que nos permitirán contex. tualizarla.

La primera se refiere a los antecedentes materiales del proyecto. La propuesta de su diseño surge, en la Direccion Xeral de Patrimonio Histórico é Documental de la Conselleria de Cultura, Xunta de Galicia. con el propósito de divulgar los resultados de las investigaciones arqueológicas que, bajo su tutela, realizan en la zona varios grupos de investigación de la Universidad de Santiago ${ }^{2}$.

Con esta perspectiva, la Conselleria de Cultura propuso al ayuntamiento de Toques la conveniencia de elaborar un plan para la revalorización social del patrimonio arqueológico localizado en el ámbito territorial del ayuntamiento (fig. 1). La conformidad de ambas instituciones en este propósito se materializó en la firma, en julio de 1992, de un convenio de colaboración entre ambas para abordar la elaboración del mencionado plan. Posteriormente,

${ }^{2}$ Estos son los que bajo la dirección de F. Criado Boado desarrolla el proyecto Arqueologia del Paisaje: El áré BoceloFurelos, y el que bajo la dirección de F. Acuna Castrovicjo lleva a cabo el de $A$ ocupación do expacio no mundo antigo no val do Furelos. en noviembre de 1992. sera firmado un segundo acuerdo entre el ayuntamiento y la universidad de Santiago al objeto de que el proyecto fuese acometido por los equipos de investigación que trabajan en la cona!

La segunda precision se refierc a la genealogia de este trabajo, derivación de una estrategia de investigación. la Arqueologia del Paisaje (en adelante ArPa). cuyos planteamientos teóricos. metodológicos y practicos han sido convenientemente desarrollados en diversos trabajos de F. Criado Boado (Criado, 1988: 1994: Criado et alii, 1992) y en un trabajo anterior (Criado y Gonzalez, 1994) en el que se discutieron las posibilidades que ofrece la Arqueologia del Paisaje para basar en ella estrategias de rentabilización social del Patrimonio Arqueológico, y se formularon las bases teóricas que fundamentan la rentabilizacion patrimonial desde esta perspectiva de trabajo.

Apuntadas las bases teoricas fundamentales de las que se nutre este texto, enunciaremos el objetivo que lo alienta y que, tal y como se puede suponer después de este preámbulo. es el siguiente:

Definir v comentar el diseño de un programa de acción para la conservación. mantenimiento y divulgación del patrimonio arqueológico de una zona rural, capaz de atraer visitas que puedan funcionar como elemento de dinamizacion socio-económica 4 .

En efecto, a lo largo del articulo, describiremos cómo hemos tratado de resolver este propósito cada vez más demandado desde el conjunto social, las administraciones públicas y los mismos arqueólogos. En este sentido, debemos apuntar que nuestra propuesta es una más dentro del notable conjunto de iniciativas que encaminadas a la puesta en valor y divulgación del patrimonio arqueológico y cultural están surgiendo en nuestro Estado. En efecto. con planteamientos teóricos y objetivos materiales diferentes se comienzan a definir proyectos tales como:

- Los encaminados a recuperar y hacer accesible al público un yacimiento. Entre éstos se puede destacar la iniciativa de la Dirección General de Bellas Artes y Archivos, Ministerio de Cultura, de creación de Parques Arqueológicos (véase el volumen VVAA., 1992b).

Los costes materiales del mismo serian sufragados por la D.X.P.II.D. Conselleria de Cultura. Xunta de Galicia.

+ Una sintesis sobre el papel que el turismo rural y cultural puede jugar en el desarrollo socioeconómico de áreas rurales. asi como algunas de sus posibilidades y ejemplos concretos de actuacion puede verse en VVAA.. 1992a. 
- Los dirigidos a preservar y divulgar el patrimonio arqueológico y/o cultural de una zona (Burillo et alii, 1992; Burillo et alii, 1994; Ayoza-Royo, 1990; Carrera et alii, 1995; Gisbert, 1992).

- Los enfocados a transmitir la historia y modos de vida de sociedades pretéritas utilizando como referente la simulación y reconstrucción de yacimientos y ambientes pasados, caso del parque etnoarqueológico Reina Sofia (VVAA., 1992c), o los elementos arqueológicos y culturales inscritos en el paisaje actual de una zona (tal como es el caso del Parque Arqueológico de las Médulas, FernándezPosse, 1995).

Entre este último tipo de iniciativas puede inscribirse nuestra propuesta. Para su relato, comenzaremos por explorar el contexto legislativo y social en el que ha de desenvolverse (apartado 1). Seguidamente (apartado 2), utilizando como referente práctico el ayuntamiento de Toques, se caracterizan y valoran los elementos patrimoniales. En el apartado 3 se concretan las condiciones sociales e infraestructurales a las que se deberán acomodar los recursos patrimoniales. Finalmente (apartado 4) se expone, de forma sintética, cómo se ha concretado una alternativa para la divulgación del patrimonio de este ayuntamiento.

\section{CIRCUNSTANCIAS DEL PROYECTO: SOCIEDAD DEL BIENESTAR Y LEGISLACIÓN}

Tal y como hemos apuntado en el apartado anterior, los planteamientos teóricos que guiaron la labor de rentabilización se fundamentaron en la ArPa. Los presupuestos prácticos derivan, sobre todo, del intento de sintonizar las propuestas de la $\mathrm{ArPa}$ con el actual contexto que posibilita el desarrollo de los programas de valorización social del patrimonio.

Para precisar este contexto es necesario conocer, ante todo, las circunstancias sociales y juridico-institucionales que rodean $\mathrm{y}$, en mayor o menor medida, determinan el planteamiento y el éxito de los proyectos de recuperación patrimonial, puesto que ambas configuran el marco de la oferta y la demanda en la que surgen este tipo de trabajos. De este modo, la consideración del aspecto sociológico nos permitirá caracterizar la demanda, mientras que la del segundo, el jurídico-institucional, nos precisará las posibilidades de la oferta.
CiRCUNSTANCIAS SOCIALES: LOS NUEVOS GUSTOS DEL «URBANITA» MODELO

Dos, de entre los diversos rasgos que permiten caracterizar a nuestra actual sociedad, resultan determinantes a la hora de entender el creciente interés del gran público en el Patrimonio Cultural ${ }^{5}$. Éstos son: la «ecologización» del mundo (Mafessolli, 1994) y el gusto por el pasado.

En efecto, cuando es evidente que el desarrollo industrial del mundo occidental se realiza a costa de la destrucción del entorno físico y medioambiental, que este desarrollo tecnológico no es paralelo a un desarrollo económico y social general, que el progreso económico, politico, industrial y científico, paradójicamente, conlleva una regresión en las condiciones medioambientales y sociales de vida, se hace manifiesta una creciente preocupación por la conservación del entorno junto con una valoración negativa de los cambios consecuentes al desarrollo.

Es asi como se hace patente una «ecologización» del mundo ${ }^{6}$, un deseo de conservación concomitante con una percepción negativa del futuro y un sentimiento de nostalgia hacia el pasado.

$\mathrm{Y}$ es que, el pasado, apenas conocido pero inocuo, reelaborable a la medida de nuestra necesidad, nos devuelve la imagen, no siempre real pero acogedora, de un tiempo en el que reinaban la permanencia y lo constante ${ }^{7}$. ¿No es ésta la idea que puede ofrecer al gran público un yacimiento dispuesto para la visita, embalsamado con las más modernas técnicas de conservación, cadáver inmutable por ley aunque sea inscrito en un entorno constantemente cambiante?

\footnotetext{
sas valoraciones en torno al contexto social e institucional se harán tomando como marco de referencia el Patrimonio Cultural en general, puesto que el Patrimonio Arqueológico es uno de los diversos ámbitos que lo componen y, como tal, participa de similares circunstancias.

- Una investigación del Mori Social Research Institute de Londres apunta que, a pesar de la impresión generalizada de que los problemas medioambientales han perdido puestos en la agenda de prioridades desde la Conferencia de Río, el activismo verde está creciendo en países tan diversos como Gran Bretaña, Polonia, Méjico o Australia (Warmer Bulletin, 1995).

7 Según apunta Prentice $(1993,22)$, el consumo del Patrimonio podría ser interpretado como un indicador del incremento de la nostalgia por aspectos del pasado vistos como permanentes y tranquilizadores, y aunque para algunos sociólogos como Braudillard (1993) esta nostalgia por el pasado es cuando menos sospechosa de pérdida de la memoria colectiva y la tradición que desaparecen para reaparecer convertidas en objeto folclórico, hemos de reconocer que beneficia a ciertos grupos, entre los que se encuentra el de los arqueólogos.
} 
Con este ambiente de fondo surge un demandante-tipo ${ }^{*}$ que se corresponde con el urbanita modelo: consumidor insatisfecho, ecologista amante del reciclado, ocioso infeliz en su abundante tiempo libre y confundido en la progresiva aceleración de lo cotidiano. A él se le ofrece el pasado (al igual que lo verde y lo light) como objeto consumible, transformado en los más variados productos: novelas, peliculas, viajes...

Se entiende asi la creciente demanda de otras geografias, espacios y tiempos de ocio que se concretizan en lo que genéricamente podemos llamar turismo rural y/o cultural: un tipo de ocio activo, que busca el contacto con la cultura de la zona sobre la que se desenvuelve y un entorno bien conservado (Cánovas, 1993; Lafuente, 1993).

Además, como consecuencia de las ventajas sociales y económicas que proporciona, el turismo rural y cultural es potenciado desde las distintas administraciones (locales, autonómicas, estatales e incluso europeas ${ }^{9}$ ), como una posible vía de futuro, fundamentalmente para el medio rural sumido, desde hace años, en una insuperable crisis de superproducción agrícola.

Así, al hilo de la creciente demanda urbana y de la promoción y desarrollo de nuevos modelos de ocio, el Patrimonio Cultural adquiere un papel fundamental puesto que la solicitud de lugares y objetos de significación histórica, artística, etnográfica o ambiental es cada vez mayor.

\section{CIRCUNSTANCIAS LEGALES: EL MARCO LEGISLATIVO Y JURIDICO-INSTITUCIONAL}

Para caracterizar el marco legislativo nos centraremos sobre todo en dos aspectos: el concepto de propiedad en el Estado Español y la actual legislación que posibilita la gestión de los bienes culturales.

\footnotetext{
${ }^{*}$ No existen muchos estudios de detalle que permitan aislar perfiles concretos de demandantes-tipo para cada uno de los diferentes ámbitos y tipos de disposición al público de lo patrimonial. Sin embargo, se puede esbozar el perfil genérico del turista o visitante cultural, trabajador no manual, de clase media, procedente de medios urbanos y de todas las edades (Prentice, 1993, 51-66). Similares características sugiere el estudio realizado por la CC.AA. de Navarra para los visitantes al Pirineo Navarro, individuos procedentes de CC.AA. de gran concentración urbana (Pais Vasco, Madrid o Cataluña), de entre 26-35 años y de clase media alta en la que abundan los profesionales técnicos, administrativos y enseñantes (Guijarro, 1995,12).

${ }^{9}$ En el contexto.de la U.E. puede verse muy claramente en el extenso informe de la Comisión de las Comunidades Europeas sobre Las acciones comunitarias que afectan al turismo (COM 94; 74 final), así como en la promoción y desarrollo de los programas Leader e Interreg.
}

En lo que respecta al primero, cabe decir que en un Estado Social de Derecho, como es el Estado Español, la propiedad ha dejado de ser un derecho absoluto para adquirir un carácter limitado en función del interés social (Barrero, 1990, 319-47). Si bien ésta es la filosofia que desde un punto de vista general rige nuestro ordenamiento juridico, en la inmensa mayoria de los ciudadanos, al menos en Galicia, continúa operando la idea, generada al abrigo del estado liberal del siglo xix, de que la propiedad confiere a su poseedor un derecho absoluto de uso.

Trasladando estas ideas al ámbito del Patrimonio Cultural, se puede decir que si bien la legislación mantiene su uso y disfrute como un derecho de la colectividad ciudadana, con independencia de que ese patrimonio sea de titularidad pública o privada, el titular privado de bienes culturales aspira a mantener un derecho exclusivo de uso.

Es asi como, bajo este doble interés que enfrenta lo social y lo individual (Tallón, 1991), resulta fácil entender las contradicciones que se generan entre los principios juridicos que regulan la actuación sobre el patrimonio y la praxis de su gestión; entre los derechos a su disfrute por parte de la colectividad y los que para el titular del bien se derivan de su derecho de propiedad; o, entre las obligaciones del propietario respecto a ese bien y las de la administración como depositaria de los intereses de la comunidad.

Si pasamos a examinar el segundo aspecto, el marco legislativo, se debe apuntar que los mecanismos legales de actuación sobre los bienes culturales se encuentran dispersos en distintas normativas que, a su vez, atañen a instancias muy diversas: administración central, autonómica, local, particulares..., lo que en ocasiones los convierte en inoperantes para la gestión de los bienes y, en todo caso, dificulta las actuaciones integrales sobre distintos ámbitos de lo patrimonial.

Esta coyuntura es tanto más grave cuanto que, de la actual concepción del Patrimonio Cultural como un todo en el que tiene cabida cualquier aspecto que pueda ser relevante para el conocimiento y acercamiento a una cultura, se deriva la necesidad de una gestión integrada de todos su ámbitos.

El corolario de esta situación es que si de las demandas sociales puede derivarse un prometedor panorama para la conservación, gestión y puesta en valor de los bienes culturales, las posibilidades que desde el marco jurídico-administrativo se ofrecen para vertebrar la actuación sobre ellos, se encuentran dominadas por la intervención de intereses dispares (públicos y privados) y por la desconexión entre 
los planteamientos jurídicos y los instrumentos de actuación que desde éstos se ofrecen.

Así este examen, además de aproximarnos al medio en el que actualmente se desenvuelve la gestión de los bienes culturales, permite extraer una consecuencia importante como es que cualquier propuesta de actuación sobre ellos debe concretarse en acciones que, al mismo tiempo que satisfagan las demandas sociales, puedan ser consensuadas entre las diferentes instancias con capacidad de intervención en su ámbito de acción.

\section{LOS RECURSOS DEL PROYECTO: LOS ELEMENTOS PATRIMONIALES Y EL NECESARIO ESTABLECIMIENTO DE CRITERIOS PARA SU VALORACIÓN}

Una vez efectuada una aproximación al medio en el que han de desenvolverse las propuestas de revalorización patrimonial, nuestro siguiente paso en la definición de una estrategia de acción para la revalorización del patrimonio arqueológico del ayuntamiento de Toques, consistió en valorar la potencialidad de los recursos patrimoniales.

Esta caracterización y valoración del conjunto patrimonial junto con la de las circunstancias geográficas, sociales e infraestructurales que pueden intervenir en el desarrollo de nuestra propuesta, permitiria descubrir tanto las ventajas y oportunidades que pueden ser potenciadas como las carencias que habrán de ser subsanadas a la hora de diseñar la estrategia concreta de acción. La acomodación de ésta a ambas circunstancias, las patrimoniales y las geográficas, es lo que permitirá asentar el diseño del proyecto sobre criterios realistas.

Esta parte del trabajo, en el caso de Toques, fue elaborada con especial detalle puesto que la realización de varias campañas de trabajo arqueológico nos permitió disponer de un pormenorizado conocimiento de la zona tanto patrimonial como geográfico.

En lo que se refiere a los recursos patrimoniales, debemos apuntar que si bien la recuperación debía centrarse en un terreno muy concreto del Patrimonio Cultural, el arqueológico, la actual concepción integral del Patrimonio Cultural ${ }^{10}$, la interconexión

\footnotetext{
${ }^{10}$ Esta concepción parte, fundamentalmente, del reconocimiento de que la división entre Patrimonio Natural y Cultural es artificiosa, puesto que el Patrimonio Natural como todo lo que tiene que ver con el hombre es ante todo Cultural (Criado y González. 1994). Asimismo, la extensión del campo fenoménico del Patrimonio Cultural contribuye a difundir la necesidad de pensar cualquier aspecto de lo patrimonial (arqueologia, arte, arquitectura, paisaje, etc.) como parte de un todo más amplio que es la cultura.
}

entre sus diferentes ámbitos, la oportunidad de diversificar la oferta de cara a la atracción de amplios sectores de público y la fundamentación de nuestros principios de acción en la ArPa (Criado y González, 1994), impuso la necesidad de valorar otros ámbitos que pudiesen contextualizar y complementar al arqueológico.

En función de este planteamiento se realizó una valoración del Patrimonio Arqueológico, Histórico, Etnográfico y Natural junto con otros recursos, como la artesania, que pudiesen ser integrados en el conjunto de valores culturales de la zona. Para ello, comenzamos por hacer una evaluación del conjunto de los elementos para, posteriormente, seleccionar los que se proponian para su revalorización.

Antes de entrar a comentar el alcance de estos trabajos, creemos oportuno hacer una reflexión sobre el método o, mejor dicho, sobre la falta de método con que generalmente los abordamos.

$\mathrm{Y}$ es que el actual afán preservacionista, junto con la creciente querencia social hacia las atracciones culturales, ha obligado a las distintas administraciones e instancias con competencias en el ámbito patrimonial a plantearse la necesidad de definir criterios para evaluar la importancia de los elementos patrimoniales de cara a su preservación y revalorización.

Sin pretender profundizar en un tema cuya extensa problemática daría pie a otro trabajo distinto, nos interesa destacar la urgencia de esta labor porque mientras aún no se ha llegado a una formulación de criterios para evaluar la importancia de los bienes culturales que pueda ser generalmente validada, muchos lugares y elementos, tanto ambientales como históricos, son elegidos como objeto de inversión con la finalidad de ser convertidos en puntos de atracción pública.

Amparándose en inmejorables motivaciones como pueden ser la urgencia social, o las pésimas condiciones para la preservación del bien ", se invierten considerables esfuerzos en monumentos, yacimientos, parques naturales, etc., sin que previamente medie una objetivación de sus potencialidades y/o sin una finalidad social claramente definida, lo que asimismo conlleva la inexistencia de un adecuado plan de gestión.

Dado que esta problemática no es solventable desde una perspectiva individual (esto es, cuando como profesionales nos enfrentamos con la rentabilización de un elemento o conjunto de elementos

"Incluso a veces, tratando de corregir algunas actuaciones
responsables o realizadas bajo criterios distintos a los actuales. 
concreto), sino que más bien es un problema de politica de gestión que atañe a las administraciones depositarias de la custodia de los bienes, resulta cada vez más urgente definir criterios que puedan ser consensuados y validados por todas las instancias con intereses en estos temas.

Se podrian alegar múltiples razones que hacen dificil consensuar un sistema que permita establecer rangos entre yacimientos y criterios para su selección, tales como pueden ser la carencia de un inventario actualizado, la inoperancia de las múltiples escalas de análisis posibles (estatales, comarcales, autonómicas...), la dificultad de caracterizar ámbitos distintos dentro de lo patrimonial (decidir dónde acaba lo arqueológico y empieza lo artistico...), la mutabilidad de principios de acción tan variables como dinámica es la sociedad que los valida..., pero todas ellas no son sino cuestiones a las que dar respuesta a la hora de desarrollar modelos de evaluación y selección que nos posibiliten tomar decisiones sobre el futuro de los valores culturales fundamentadas en criterios coherentes, mensurables y consensuados ${ }^{12}$.

Apuntada la carencia fundamental para abordar una valoración y posterior selección de recursos, seguidamente comentamos cómo se ha tratado de solventar para el caso que nos ocupa.

Patrimonio Arqueológico: La abundancia de investigaciones que desde principios de siglo se han sucedido en la zona ${ }^{13}$ constituye una primera muestra del interés de este conjunto, aunque será sobre todo a partir de 1987, cuando se incremente de forma cualitativa y cuantitativa su entidad (fig. 2).

Estas investigaciones, dieron lugar a un relevante conjunto de valores, fisicos e intelectuales, de gran

\footnotetext{
${ }^{12}$ Intentos de este estilo están siendo abordados por otros estados europeos como el británico, que ha desarrollado un complejo sistema de graduación de elementos del patrimonio histórico (Lambric, 1992) como parte de su Programa de Protección de Monumentos, aunque se le reconoce la necesidad de criterios más claros y explicitos para la evaluación integrada de los valores ambientales e históricos. Criticas más generales (Prott, 1992; Boyer, 1993) recibe la lista de Patrimonio de la Humanidad de la UNESCO. Éstas van desde la divergencia de criterios entre sus dos instancias evaluadoras, el ICOMOS para el patrimonio construido y el IUNC para el medioambiental, hasta su ineficacia. Sin embargo, todos estos intentos resultan loables en la medida en que generan la discusión y acaban por centrar la atención social y de las administraciones responsables. En nuestro estado comienzan a verse intentos de este estilo, como es el trabajo de Carrera y Barbi (1992) para el patrimonio arqueológico.

13 Entre los precursores de estas investigaciones cabe destacar los trabajos de Álvarez Carballido en la década de los 20-30, junto con los abordados por el Seminario de Estudios Galegos, cuyos resultados dieron lugar a la publicación, en 1933, de $T e$ rra de Melide.
}
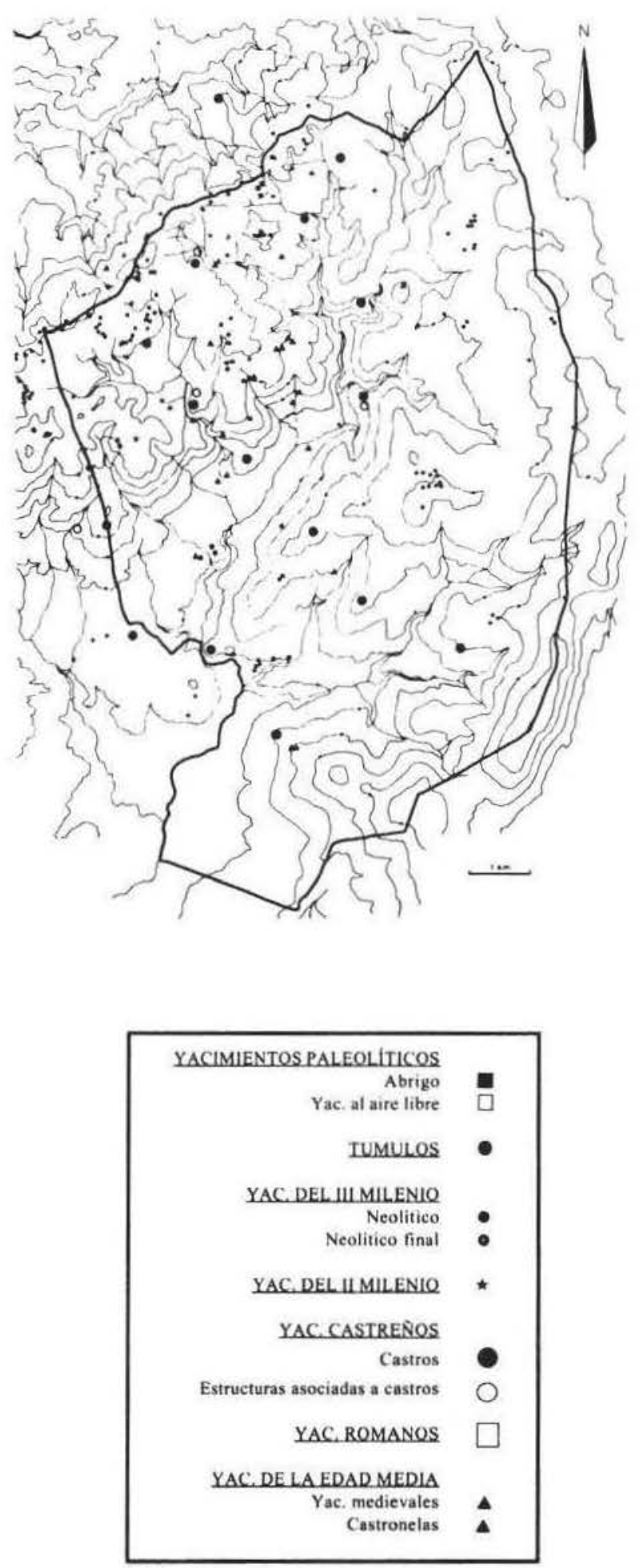

Figura 2.-Distribución de yacimientos y puntos arqueológicos del municipio de Toques. 
utilidad para el diseño de nuestro proyecto. En efecto, a los mas de cien puntos arqueologicos ${ }^{17}$ correspondientes a las principales etapas de la prehistoria (valores fisicos). se sumaba el conocimiento derivado de los analisis $\mathrm{e}$ interpretaciones surgidos del estudio de estos puntos (valores intelectuales).

Es asi como, por poner un ejemplo, se podia destacar la localización de un importante numero de puntos arqueológicos de tipologias y cronologias escasamente representadas en el conjunto de Galicia ${ }^{14}$. junto a la existencia de un modelo interpretativo de la utilizacion y aprehensión del espacio por parte de estas comunidades en la zona (fig. 3 ).

Es la conjuncion de estos dos tipos de informacion. registro arqueologico bruto e interpretacion que le otorga significacion a ese registro. Io que constituyo la materia prima básica para el proceso de valoracion del comjunto arqueológico.

Partiendo de este planteamiento. examinamos el conjunto de la documentación generada por las labores arqueológicas. Esto implicó:

1) Examinar el registro: esto es, yacimientos y elementos arqueológicos.

2) Revisar los datos y conocimientos existentes en torno a ese registro.

3) Efectuar su valoración arqueológica. Esto significa extraer las consecuencias que, desde el punto de vista de la investigación y del interés patrimonial, se derivan de los dos tipos de información anterior (si se trata de yacimientos o simples puntos de aparición de material, su estado de conservación. etc.).

Abordado este examen, el siguiente paso fue seleccionar la documentación en función de su interés para un público mayoritario y no especialista. En esta labor, harto compleja, intervienen variables de dificil cuantificación y por supuesto cambiantes, tales como pueden ser: el interés histórico o estético del bien, su valor económico, su carảcter singular respecto al conjunto que se valora, las demandas y preferencias del público... Sin embargo, dentro de un contexto concreto, definido a partir de la interacción de las variables anteriores y circunscrito a un

\footnotetext{
14 Por punto arqueológico entendemos cualquier punto del espacio en el que se documente la existencia de elementos arqueológicos, independientemente de la naturaleza de éstos y del carácter de su presencia; en esta definición tienen cabida desde yacimientos primarios hasta débiles huellas de ocupaciones esporadicas (Criado et alii, 1992, 60-1).

14 Nos referimos en concreto a los yacimientos de épocas paleoliticas o epipaleoliticas y a los hábitats del momento megalitico, neolitico y edad del bronce.
}

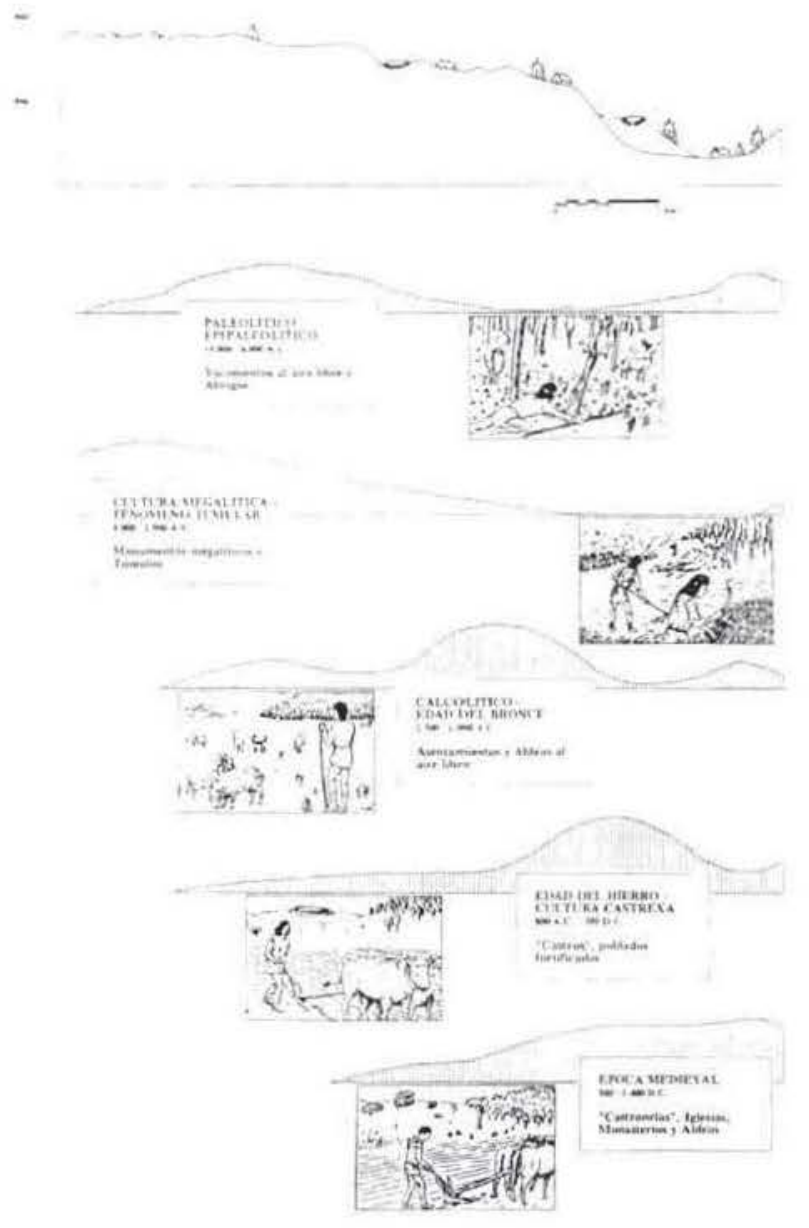

Figura 3. Modelo interpretativo del patrón de poblamiento del ayuntamiento a lo largo de diferentes momentos prehistoricos e hisloricos. El corte superior (perfil del municipio) sirve de base a los siguientes en los que se representa. con una mayor altura e interlineado. el piso topografico ocupado en cada uno de los momentos representados.

espacio socio-geográfico determinado, es posible delimitar el alcance social de los elementos arqueológicos.

En nuestro caso, además, el hecho de contar con interpretaciones y conocimiento en torno a los bienes patrimoniales, nos permitió introducir a estas interpretaciones como otro factor más de delimitación del interés social. Para ello, sin embargo, fue preciso que este conocimiento se concretase en una narrativa sugerente e ilustrativa para el público.

De este modo, la determinación del interés del Patrimonio Arqueológico de Toques, se abordó desde una escala concreta, la municipal, y en función de los factores clásicos anteriormente mencionados. contando además, con la narrativa que sobre este patrimonio se pretendia comunicar.

Introducir la necesidad de una narrativa a la hora de realizar la selección de los bienes nos parece una 
cuestión fundamental puesto que supone una inversión metodológica importante a la hora de abordar un proyecto de rentabilización. Esta narrativa, surgida de la investigación y expuesta de forma comprensible al público, es lo que confiere sentido al bien y por lo tanto puede servirnos como uno de los criterios de selección puesto que se hace evidente en distintos grados en cada uno de los elementos arqueológicos ${ }^{16}$.

Sin embargo, esta narrativa o interpretación ${ }^{17}$ generalmente, y es aqui donde planteamos invertir la forma tradicional de trabajo, se define a posterio$r i$, cuando el bien ya ha sido seleccionado en función de los criterios clásicos al uso ${ }^{18}$. Esta concepción del trabajo parte de la idea de que el vestigio arqueológico tiene un valor en si mismo y que este valor es consustancial a la materialidad de ese vestigio y más perceptible cuanto más grande, estético o bien conservado se nos muestre, cuando en realidad, lo que ocurre es que el valor del vestigio existe en tanto en cuanto el arqueólogo puede interpretar y desentrañar el sentido del vestigio y en tanto en cuanto tiene capacidad para comunicar al y con el público actual ${ }^{19}$.

En función de este planteamiento realizamos una reformulación del registro de cara a definir las entidades espacio-culturales que permitiesen al público acceder a la lectura que en torno al conjunto arqueológico le proponiamos. A estas entidades las denominamos conjuntos patrimoniales de interés socio-cultural. La asunción de esta estrategia de definición de conjuntos para la valoración de la relevancia social de un conjunto patrimonial tiene cuatro implicaciones importantes:

\footnotetext{
th Tal y como apuntan Garcia y Caballero (1992), es necesario que el visitante reconozca los elementos que ve y que los identifique con la narrativa o mensaje que se pretende ilustrar, puesto que, en el tema que nos ocupa, la percepción visual es el punto de partida del conocimiento.

17. Término actualmente utilizado por los técnicos en difusión y divulgación del patrimonio cultural.

18 Nos referimos sobre todo a las rentabilizaciones de otros paises europeos, como pueden ser Francia o Inglaterra. En nuestro país, si consultamos las últimas propuestas de rentabilización de yacimientos y monumentos (Barbi et alii, 1995; VVAA., 1992b), se plantean sobre todo las necesidades que tienen que ver con el buen estado y conservación del vestigio y con los sistemas y tecnologias para su difusión, reduciendo a un segundo plano, e incluso obviando, la narrativa o sentido que a través de los bienes y şu estudio los especialistas debemos transmitir.

19 No podemos dejar de apuntar aquí una paradigmática anécdota, como es que ante los restos de un yacimiento integrados en un jardín un visitante que nos acompañaba, biólogo de profesión y que como tal no reconoció el vestigio, nos dijo que la «escultura» le gustaba.
}

- La primera es que, así definido, un conjunto patrimonial puede estar compuesto por una o varias entidades arqueológicas, ya sean éstas verdaderos yacimientos, áreas de ocupación o simples puntos arqueológicos; incluso pueden integrarse en él bienes artísticos, históricos o medio-ambientales. Lo que realmente confiere entidad al conjunto sociocultural es su capacidad ilustrativa de la interpretación arqueológica que se desea transmitir al público (la narrativa), no su corporeidad fisica.

- La segunda es que esta formulación de conjunto socio-cultural es extensible a cualquier ámbito del Patrimonio Cultural.

- La tercera implicación es que, en la selección de los elementos del registro que integrarán el conjunto, dejan de ser fundamentales las cualidades estéticas, monumentales o singulares para posibilitar la introducción de elementos menores que permiten conformar y dar a conocer una imagen global del contexto arqueológico.

- La cuarta implicación es que, para la definición de un conjunto resulta imprescindible la introducción de una interpretación histórica que, otorgando un sentido a los elementos de ese registro, permita ordenarlos en función de su capacidad de comunicación.

Entre los conjuntos así definidos, en una fase posterior de trabajo que más adelante comentaremos, se seleccionaron aquellos que iban a ser puestos a disposición del público.

Patrimonio Histórico y Etnográfico: Las consideraciones hechas en el subapartado anterior sobre la valoración del interés social del patrimonio arqueológico son extensibles a la valorización de cualquier bien cultural. Sin embargo, debemos apuntar que en el caso concreto del proyecto de Toques no se han aplicado con un grado de detalle similar al arqueológico. Ello fue así no sólo porque nuestra formación en la disciplina arqueológica nos situaba en una posición de desventaja para abordar este trabajo, sino que además intervienen las razones que seguidamente comentamos:

1) Sobre estos bienes no existía una inversión de trabajo y estudio previa de envergadura similar a la existente en torno al patrimonio arqueológico.

2) Su entidad, después de realizado un examen preliminar, tanto de los bienes como de la documentación existente sobre ellos, resultaba muy limitada.

3) Finalmente, el hecho de que el objetivo fundamental del trabajo fuese la revalorización 
del patrimonio arqueológico llevó a la consideración de los restantes ámbitos en la medida que complementasen y contextualizasen a los arqueológicos.

Vistos los condicionantes y presupuestos que guiaron la valoración de estos ámbitos pasamos a sintetizar el resultado de su examen.

El Conjunto Histórico del ayuntamiento no resulta especialmente relevante por su número de elementos. Estos se reducen a cuatro iglesias, y a cinco casas grandes o hidalgas (que no llegan a la categoria de pazos). Sin embargo, cuenta con un momumento de gran singularidad en el conjunto de Galicia como es la iglesia pre-románica de San Antolin, en la actualidad declarada $\mathrm{BIC}^{20}$.

En lo que respecta al Conjunto Etnográfico cabe realizar una valoración similar a la del conjunto anterior. Su arquitectura popular es una muestra de la arquitectura tradicional de la comarca en la que se inscribe el ayuntamiento, A Terra de Melide. Como elementos más relevantes se pueden destacar los hórreos de mimbre, la existencia de molinos de agua, aún en funcionamiento, o una buena red de caminos antiguos como pueden ser el camiño de Ovedo (importante itinerario de peregrinación a Santiago en época medieval y posiblemente via romana (Ferreira, 1988, 192; Gómez, 1994), o el camiño real de $O$ Bocelo, camino de acceso a uno de los conjuntos megalíticos más interesantes de la zona.

El medio natural (Giménez de Azcárate et alii), si bien no posee áreas de interés que pudiesen ser calificadas de excepcionales en el conjunto de Galicia, se beneficia de una diversidad geológica, morfológica y edafológica que unida a la particular acción de sus habitantes ha dado lugar a variados paisajes y circunstancias ecológicas. Lo más destacable es que se trata de un medio sin grandes alteraciones, en el que se encuentran algunas especies incluidas en los catálogos de protección de distintos organismos, junto con algunas de gran valor corológico y bio-indicador.

En un proyecto de este tipo, creemos también importante valorar la producción artesanal ya que ésta incrementa de forma notable los recursos explotables turísticamente. Sin embargo, en Toques su valoración debe ser negativa puesto que, además de no existir ninguna escuela o tradición artesanal, las pequeñas producciones comercializables en los mercados locales (lino, cestas, zuecos, miel...) han desaparecido casi en su totalidad.

\footnotetext{
20 Declaración en la que se le reconoce como monumento, sitio histórico y zona arqueológica (D.O.G., núm. 121, 24 junio de 1994).
}

\section{LAS BASES DEL PROYECTO: DELIMITACIÓN DE LAS CONDICIONES SOCIOGEOGRÁFICAS DE PARTIDA}

Conocer el escenario sobre el que se pretende materializar el proyecto resulta determinante a la hora de delimitar sus dimensiones y de concretar formalmente el programa de actuación que se pretende diseñar puesto que, en estas decisiones, han de tenerse presentes aspectos tan diversos como pueden ser, la situación geográfica del ayuntamiento, la disponibilidad de recursos humanos e institucionales, la capacidad de iniciativa de sus vecinos, la disposición de éstos hacia las actuaciones que conlleva su desarrollo, la existencia de las necesarias infraestructuras materiales de apoyo o el posible impacto que pueda tener el desarrollo del proyecto en la zona.

Con el objeto de descubrir las disponibilidades del ayuntamiento en estos temas se abordó una caracterización del área de trabajo deteniéndose para ello en los siguientes aspectos:

- Geografía: Toques es un ayuntamiento de la Galicia medio-interior perteneciente a la comarca de $A$ Terra de Melide y administrativamente a la provincia de La Coruña (fig. 1). Sus rasgos geomorfológicos más significativos son las sierras de $\mathrm{OBO}$ celo y $O$ Careón, límites naturales por sus lados $\mathrm{W}$, $\mathrm{N}$ y E. Entre ellas discurre, en sentido $\mathrm{N}-\mathrm{S}$, el río Furelos, afluente del Ulla que conforma un amplio y abrigado valle en el que se concentra el grueso de la población y que además vertebra el sistema de comunicaciones entre los distintos lugares habitados de la sierras.

Su situación en una zona central e interior de Galicia, le confiere una posición secundaria en la red de núcleos importantes de atracción de visitas. Sin embargo, su proximidad a puntos de interés turistico-patrimonial como pueden ser Sobrado, Melide e incluso Palas de Rey ${ }^{21}$, pueden facilitar su promoción que, por otra parte, se ve favorecida por su buena comunicación con algunas de las principales ciudades gallegas como pueden ser Santiago o La Coruña.

2 Sobrado con el monasterio de Sobrado dos Monxes, importante foco de atracción de visitas. Melide y Palas, sobre todo. porque por ellos discurre el camino francés de peregrinación a Santiago. 
- Demografía: El examen de la población ${ }^{22}$ y de su tendencia evolutiva a lo largo del último siglo muestra un continuo crecimiento hasta la década de los 60 en la que se alcanza el máximo de 3.138 habitantes. A partir de 1970, los efectivos demográficos disminuyen progresivamente como consecuencia de la caída de la tasa de natalidad y de la emigración, que si bien era importante desde comienzos de siglo se compensaba con una alta tasa de nacimientos. El resultado de este proceso a la altura de 1992 es una población de 1949 habitantes, lo que hace una media inferior a los $25 \mathrm{~h} / \mathrm{km}$, y en la que los mayores de 65 años constituyen el $22,4 \%$ de la población, mientras que los menores de 15 años son sólo el 5,6\%.

- Economía: La actividad económica del municipio se concentra en el sector primario, fundamentalmente en la ganadería vacuna de leche cuyo crecimiento ha sido el motor de modernización y desarrollo de la zona. En la actualidad, la producción láctea se encuentra frenada por las restricciones impuestas desde la CEE, y lo que es peor, no parecen existir alternativas viables para la reestructuración de un sector al que los vecinos han dedicado el grueso de las inversiones de los últimos años, muchas de ellas aún sin amortizar. La agricultura, dado lo accidentado del relieve, tiene muy poco peso en el conjunto de este sector.

Por su parte, los sectores secundario y terciario, apenas se encuentran representados, tanto por la baja demanda de un ayuntamiento escasamente poblado $y$ envejecido, como por la proximidad de un centro de aprovisionamiento importante como es la vecina villa de Melide (a sólo $6 \mathrm{~km}$ de la capital municipal).

Para finalizar el apartado económico, cabe hacer una referencia a las tasas de ocupación y paro. De acuerdo con los datos publicados para el año 1991 (IGE 1992), Toques tiene una población activa de 748 efectivos frente a 1.223 no activos (ancianos y jóvenes), mientras que sólo existen 20 demandantes de empleo.

La valoración de estas cifras apunta otro indicador más del carácter regresivo del ayuntamiento tal y como se puede derivar de una sobre-representación de la población no activa y de una importante tasa de paro encubierto. Así es, la economía de la zona basada en explotaciones agricolas de tipo familiar, mantiene un número importante de jóvenes,

22 Para componer este apartado y los siguientes de este epigrafe han sido utilizadas, además de los datos directos proporcionados por los vecinos de la zona, diversas publicaciones estadísticas del INE (Instituto Nacional de Estadistica) y del IGE (Instituto Gallego de Estadistica). no inscritos en el INEM, ayudando en las faenas del campo mientras no encuentran un trabajo remunerado, aun cuando su fuerza de trabajo no es imprescindible en la granja familiar.

- Situación socio-cultural y servicios: El nivel cultural de la población es muy bajo, tal y como lo puede avalar la existencia de un $7 \%$ de analfabetos y sólo un 1,5\% de habitantes con estudios superiores. La existencia de cinco escuelas unitarias frente a un sólo centro en el que se imparten todos los niveles de la EGB, que además no cuenta con los recursos suficientes para impartir las clases individualizadas por niveles, muestra la dureza de las actuales condiciones educativas de la población infantil. $\mathrm{La}$ inexistencia de medios de transporte públicos para continuar la formación secundaria en otros municipios reduce al mínimo su seguimiento.

Al igual que los culturales, los restantes servicios municipales como pueden ser la recogida de basuras, alcantarillado, la atención sanitaria, o el telefónico, son deficitarios.

Los datos resumidos permiten realizar algunas consideraciones en torno a los recursos humanos y bases institucionales con que puede contar el ayuntamiento a la hora de abordar las actividades que conlleva la valorización arqueológica de la zona. En éstas, se pueden incluir desde las directamente relacionadas con la gestión y conservación del conjunto patrimonial hasta cualquier servicio complementario de atención al visitante.

La primera consideración es que, si bien Toques cuenta con el suficiente capital humano, en términos numéricos, para abordar cualquier actividad relacionada con la materialización de las propuestas de acción que se prevean abordar, éste carece de cualificación. De otra parte, el envejecimiento de la población, su escasa capacidad económica y la pervivencia de una mentalidad derivada del modo de ser campesino tradicional, hace que la iniciativa privada sea muy baja para abordar el tipo de acciones que la materialización del proyecto podría requerir.

Estas circunstancias determinan que las primeras acciones de valorización, destinadas a la atracción de público, deban surgir de la iniciativa pública. Cuando sus resultados comiencen a ser percibidos (afluencia de visitas y demanda de servicios por parte de éstas), la iniciativa privada buscará un papel activo en estas empresas.

Finalmente, procede definir las bases institucionales que deben estar implicadas en el proyecto. La diversidad y amplitud de su ámbito de actuación llevan a proponer la necesidad de encontrar un espacio de opinión y acción para la multiplicidad de ins- 
tancias (públicas y privadas) que se puedan involucrar en su materialización.

Entre todas, debe destacarse la corporación municipal puesto que posee competencias prácticamente en todos los ámbitos de acción del proyecto, desde los estrictamente patrimoniales hasta los relacionados con el turismo y los servicios ${ }^{23}$. De estas competencias se deriva su papel fundamental en: la protección del patrimonio que se pretende divulgar, la promoción de bienes y servicios y la mediación entre los intereses vecinales y las instancias de ámbito supralocal que puedan intervenir en el desarrollo del proyecto (González, 1994). A la luz de lo que se acaba de comentar se podrá entender que la materialización del proyecto dependerá, sobre todo, de que su oportunidad y necesidad sea asumida por la corporación municipal.

Otras instancias que por sus intereses, trabajo o proximidad al ayuntamiento pueden tener un espacio de opinión y acción en el ámbito de un proyecto de valorización patrimonial pueden ser los ayuntamientos vecinos, la administración autonómica y, en el caso concreto de Toques, la Universidad de Santiago y el IDC ${ }^{24}$.

\section{EL DISEÑO DEL PROYECTO: LA CONCEPCIÓN Y PROGRAMACIÓN DE ACTUACIONES}

El recorrido efectuado hasta este punto podría definirse como una exploración de todos aquellos aspectos que pueden intervenir $\mathrm{y} / \mathrm{o}$ condicionar la formalización de un proyecto de este tipo. Así, una vez valorados sus resultados, se llega al punto en que es posible concretar tanto el argumento que dote de sentido a la puesta en valor de los elementos arqueológicos, como la forma en que se podrá materializar ese argumento. Este trabajo es lo que constituye la fase de diseño propiamente dicha. En ella se pueden diferenciar dos tipos de labores distintas que a continuación trataremos: la concreción de la narrativa que es posible desentrañar al conjunto patrimonial y la programación de actividades que permitirán explicitar esta narrativa al público.

\section{LA CONCRECIÓN DE LA NARRATIVA}

Tal y como se ha argüido en Criado y González, 1994, la revalorización fundamentada en la ArPa parte del planteamiento de que, puesto que desde la ArPA se estudia cómo se plantea en cada momento de la historia la interrelación entre el ambiente, los procesos sociales y el entramado simbólico-cultural de toda sociedad, cuando fuera posible reconstruir tiempos pasados, debería ser posible evocar espacios pretéritos.

La alternativa que desde este planteamiento se propone es reconstruir y ofrecer al público una narrativa basada en los valores intelectuales producidos en el desarrollo de esta línea de investigación utilizando como soporte los monumentos y elementos culturales. Asi, no se trata de mostrar yacimientos excavados como si fuesen objetos mudos de tiempos pasados, se trata más bien de evocar espacios sociales en los que los yacimientos y monumentos son sólo una parte de ese paisaje.

Desde este planteamiento, para conducir las acciones diseñadas para la divulgación del patrimonio arqueológico del ayuntamiento de Toques se propuso el siguiente argumento:

A lo largo de la prehistoria la presencia del hombre se ha hecho cada vez más clara y dominante sobre la tierra.

Este hecho podía transmitirse de forma sencilla al gran público mediante la ilustración de diferentes paisajes arqueológicos ${ }^{25}$ que muestren cómo los monumentos artificiales, obras y construcciones sobre el medio surgen en un momento tardío de la historia de la humanidad, cómo estas actividades sobre el medio natural tienen cada vez una mayor envergadura y responden a causas e intenciones sociales concretas.

En definitiva, se trata de, a través de esos paisajes, reconstruir y descubrir al público las características esenciales de cada una de las principales fases de la prehistoria e historia de la zona de trabajo. Concretamente en Toques se diferenciaron siete fases representadas por un conjunto de 108 yacimientos que van desde el paleolítico superior hasta época medieval.

Para ilustrar este argumento a través de la evocación de los paisajes prehistóricos, se han selec-

\footnotetext{
${ }^{25}$ Para ilustrar estos paisajes se utilizará como recurso básico las condiciones de visibilidad del registro arqueológico, que tal y como se argumenta en Criado, 1993, pueden ser un recurso para interpretar el registro arqueológico y acceder, a través de su estudio, a las diferentes racionalidades que lo generaron.
}

\footnotetext{
${ }^{23}$ Tal y como se desprende del art. 25.2 de la Ley $7 / 85$ Reguladora de las Bases del Régimen Local.

24 Instituto de Desarrollo Comunitario, organismo que gestiona el proyecto de desarrollo rural Leader de Portodemouros, en el que se integra el ayuntamiento de Toques.
} 


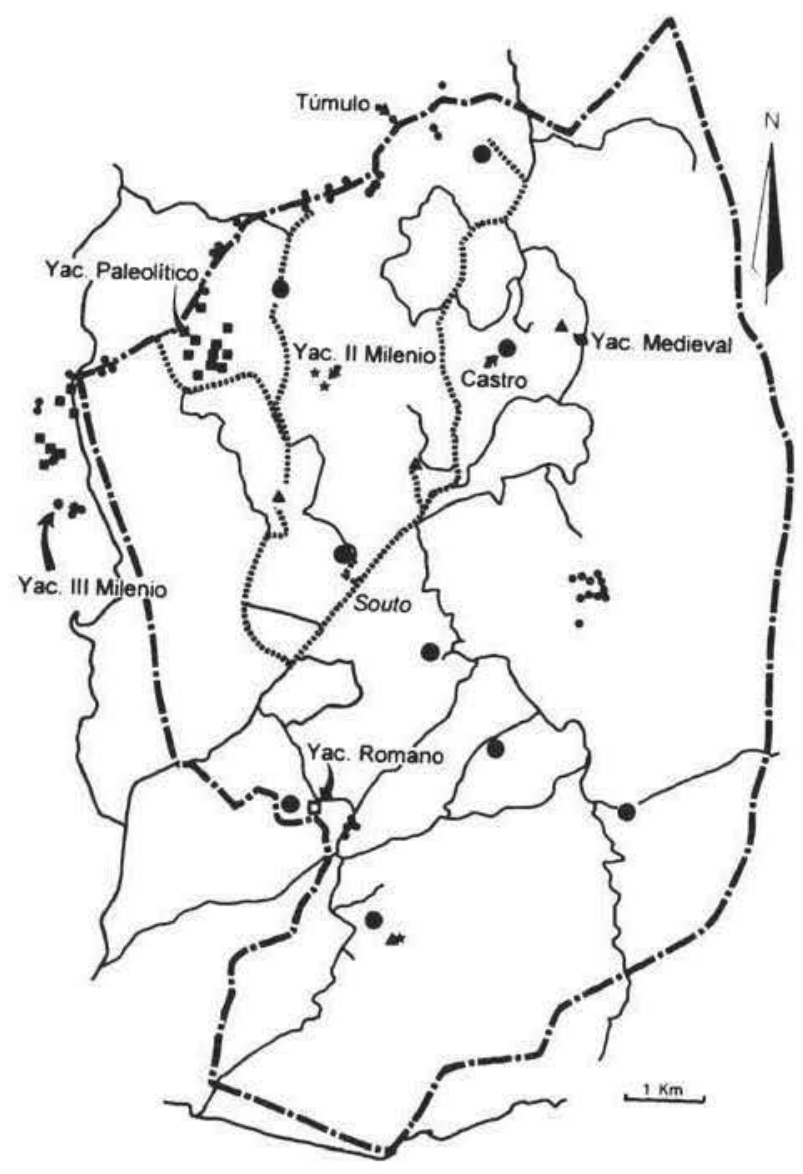

Figura 4.-Distribución de los yacimientos seleccionados para su revalorización sociocultural en la que se muestra uno de los itinerarios propuestos.

cionado veinte conjuntos patrimoniales en los que se engloban un total de 62 puntos arqueológicos (fig. 4) de distinta entidad (yacimientos, áreas de acumulación, puntos de aparición de material...). Los criterios aplicados para esta selección fueron los siguientes:

1) Adecuado conocimiento del conjunto en cuestión, bien sea a través de su excavación o de los estudios efectuados en yacimientos semejantes.

2) Que la conservación del conjunto, así como la del paisaje en el que se enmarca, sea buena o, en caso de presentar alteraciones, que éstas sean fácilmente subsanables.

3) Que sean conocidos en su ámbito geográfico inmediato o incluso más allá de él.

4) Que sean fácilmente accesibles (geográficamente hablando), por parte del público.
5) Además, se ha seleccionado un pequeño grupo de yacimientos que permiten exhibir su configuración interna: organización del espacio, tipo de construcciones domésticas..., a lo largo de los diferentes momentos prehistóricos que se pretende ilustrar.

Este grupo se constituye con yacimientos excavados, en diferente medida pero nunca totalmente. Estos yacimientos compondrán el recurso didáctico básico para la compresión tanto del momento histórico en el que se inscriben como de otros yacimientos semejantes que no han sido excavados pero que, junto con los primeros, conforman el paisaje social de cada momento histórico ilustrado.

Este primer grupo, de yacimientos excavados, se compone de ocho conjuntos, actores principales del relato. Los doce restantes, complemento importante para la evocación de los distintos paisajes prehistóricos, podrán mostrarse sin excavar, puesto que una simple limpieza de la vegetación que los cubre, o su señalización, bastan para que recuperen su aparatosidad formal y su preeminencia sobre el entorno circundante y se constituyan como jalones visibles de los paisajes prehistóricos ilustrados.

\section{PROGRAMACIÓN DE ACTIVIDADES}

Para comunicar al público la narrativa anterior se debe programar la realización de las actuaciones que compondrán el conjunto de recursos prácticos y materiales que posibiliten y amenicen la percepción individual de los restos arqueológicos. Éstas son las que en nuestro caso dieron lugar a la conformación del Area Arqueológica del ayuntamiento de Toques. En su descripción, tarea que a continuación se abor$\mathrm{da}$, se intenta reproducir el orden que debería seguir el público para acceder de la forma más adecuada a la narrativa que se le propone ${ }^{26}$. Siguiendo entonces esta ordenación se han propuesto acometer las siguientes actividades ${ }^{27}$ :

${ }^{26}$ Dado que a la narrativa propuesta se accede a través de la aprehensión del espacio, el acceso a la información debe ser organizado tomando como base esta premisa y diseñando un recorrido que permita acceder al argumento en el orden en que éste se define. En este mismo sentido se expresan Caballero y Garcia (1992), cuando apuntan que el recorrido debe ser previsto para que la información se reciba según se diseñó, puesto que el tema argumental se desarrolla a través del espacio.

27 Dado que comentar los presupuestos concretos que guiaron cada una de las actuaciones, asi como el boceto de las mismas prolongaria en exceso el texto, nos limitaremos a enunciarlas apuntando que su diseño ha sido orientado por los principios teóricos y prácticos comentados en diferentes apartados tanto en este trabajo como en Criado y González, 1994. 

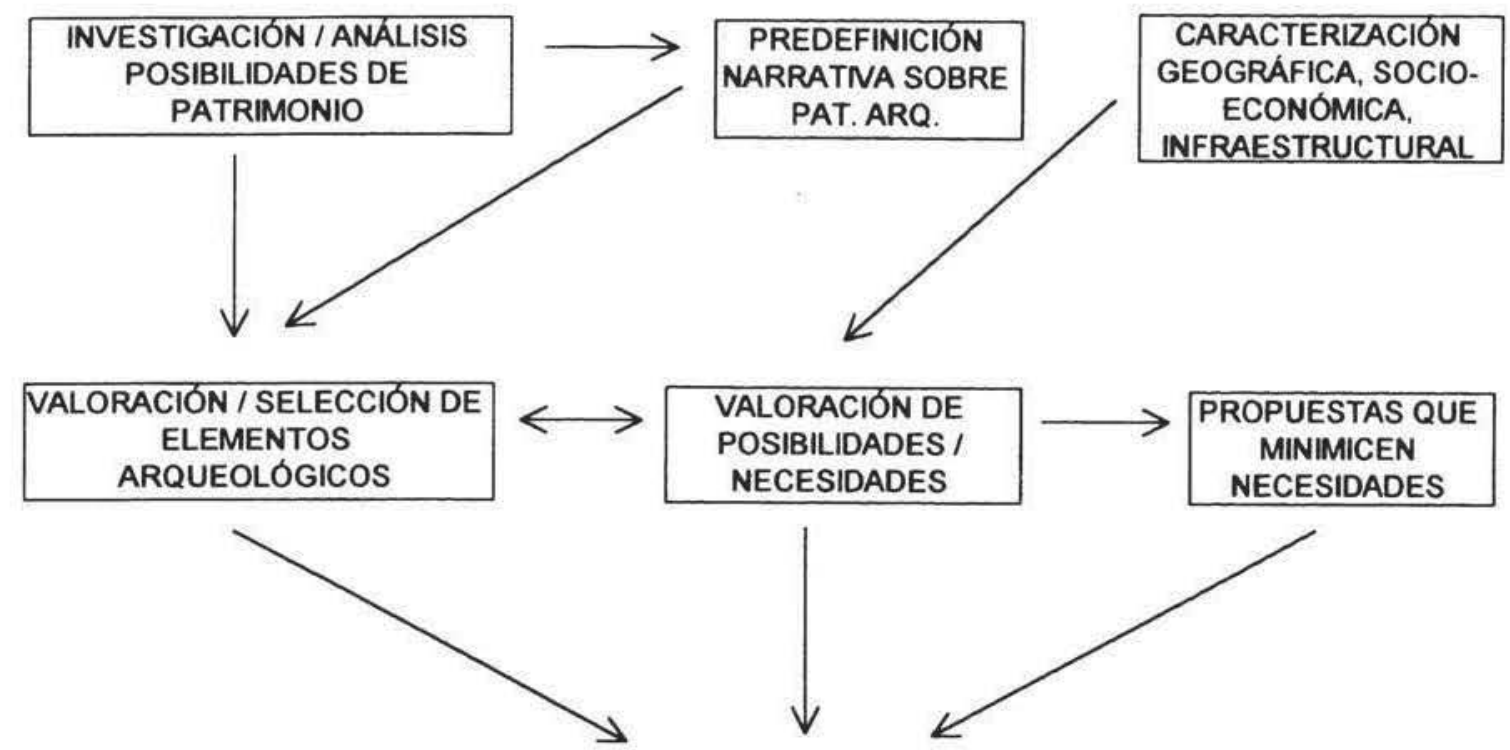

CONTEXTO SOCLAL

$$
\begin{aligned}
& \text { PROPUESTA DE ACCION: } \\
& \text { DEFINICIÓN DE NARRATIVA, } \\
& \text { DISEÑO DE ACTIVIDADES }
\end{aligned}
$$

CONTEXTO LEGISLATINO

Figura 5.-Concepción de la valorización social del patrimonio arqueológico desde los fundamentos de La Arqueologia del Paisaje.

1) Adecuar un pequeño local como centro de exposición e información acerca del conjunto patrimonial y de las posibilidades y recursos que ofrece la zona, previendo su ampliación futura para constituirse en centro de exposición permanente.

2) Preparación de una serie de publicaciones divulgativas que complementen la información que el visitante podrá obtener en el punto anterior a la vez que satisfagan otros dos objetivos: servir la información necesaria para acceder a los distintos puntos visitables de la zona y simplificar las señalizaciones sobre el terreno.

3) Definición de itinerarios de visita en coche y a pie, a distintos monumentos, yacimientos y parajes naturales de la zona. Complementados por la información que ofrecen los dos recursos anteriores, han sido pensados con carácter abierto, para permitir al visitante variar los recorridos según sus preferencias.

4) Señalización de los puntos incluidos en los itinerarios de visita.

5) Limpieza y acondicionamiento de los yacimientos y zonas de interés propuestos en los itinerarios, con el fin de adecuar los yacimientos y espacios naturales para la recepción de visitantes y hacer así posible la per- cepción del espacio y de los elementos que lo conforman.

6) Estudio y recuperación de caminos antiguos que puedan ser integrables en el conjunto histórico-arqueológico del ayuntamiento. Esta proposición deriva de tres hechos distintos:

a) constituyen la vía de acceso tradicional a muchos de los puntos visitables de la zona;

b) el senderismo es una actividad en continuo crecimiento;

c) son uno de los elementos de la geografia tradicional en vías de desaparición dada su sustitución por las modernas vías de comunicación.

7) Integración en el conjunto de la iglesia de A Capela, con la creación a su lado de un posible parque romántico, aprovechando las ruinas existentes.

8) Planificación de las consolidaciones y ambientaciones que se pueden abordar, de forma inmediata, centradas en el Castro de $A$ Graña y el monumento tumular de Forno dos Mouros.

9) Previsión de consolidaciones de yacimientos para abordar a medio y largo plazo: Pena Camposa, fig. 6 (Cerqueiro 1992), A Lagoa, Piñeiro, Os Castros y Castelo. 


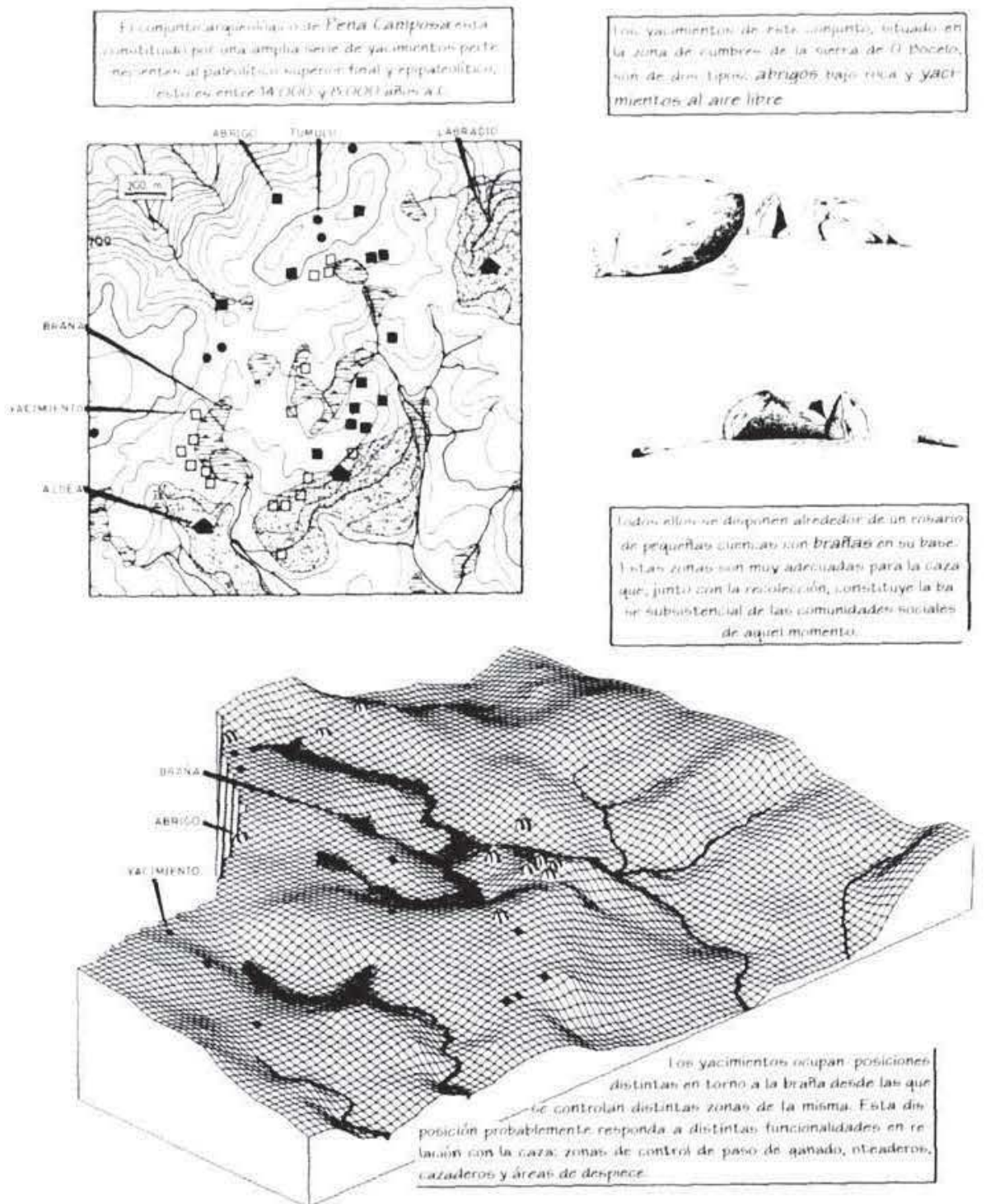

Figura 6. Ilustración del areat paleolitica de Pena Campesas. municipio de Toques.

10) En función del punto anterior, planificación de las excavaciones y estudios de interés patrimonial que seria preciso abordar como paso previo a las adecuaciones. Además de las anteriores, se tiene que prever una serie de acciones cuya realización no tiene una influencia directa sobre los yacimientos o conjuntos históricos, pero que sin embargo resultan imprescindibles para complementar el programa de ilustración y puesta en valor de espacios y paisajes pretéritos que se propone. Asi se plantea:

11) Previsión de programas de reconstrucción paleo-ambiental y de cultivos antiguos encaminados a complementar la revivificación de paisajes pretéritos (centrada hasta ahora en yacimientos y monumentos), en la actualidad desaparecidos o en vias de desaparición. Esto puede suponer, por ejemplo, la realización de estudios de Historia Moderna, Contemporánea, Antropologia, que permitan ampliar y complementar la narrativa de los paisajes pasados.

12) Preparación de diversas campañas de publicidad y divulgacion, con el objeto de promocionar la zona y atraer un amplio espectro de público.

13) Previsión de posibilidades de expansión a otros ambitos de actuación. Dado que el trabajo de valorización se centró en el patrimonio arqueológico fundamentalmente, se propone la necesidad de extender el ámbito de actuación a todos los aspectos patrimoniales susceptibles de ser potenciados.

14) Finalmente, es conveniente planificar la satisfacción de una serie de demandas de carácter general (infraestructurales, humanas y materiales) que confieran efectividad 
de las actuaciones patrimoniales. Éstas van desde la limpieza periódica de cunetas, mantenimiento y limpieza en yacimientos y puntos que puedan ser muy visitados, demarcación de áreas de interés paisajístico, adecuación de un espacio como área recreativa, rehabilitación de áreas degradadas y basureros, creación de un servicio de atención a los visitantes dotado de personal cualificado, adecuación de los servicios municipales y públicos básicos... ${ }^{2 x}$.

15) De otra parte, para la gestión y organización de las actividades anteriores será necesario crear un instrumento coordinador de todo el trabajo que implica la materialización del proyecto asi como de las instancias que en él pueden tener cabida y del equipo de trabajo que garantice la oportuna capacitación para abordar las labores patrimoniales.

\section{PLANIFICACIÓN Y ORGANIZACIÓN DE LAS DIFERENTES ACTUACIONES}

Las diferentes acciones recogidas en el programa global de actuaciones necesitan, para su desarrollo, de planes parciales de actuación que, de acuerdo con un calendario previo, deberán ser establecidos en función de criterios que pueden ser tan diversos como los antecedentes que determinan el planteamiento del proyecto.

Teniendo en cuenta que las circunstancias que pueden concurrir a la hora de establecer plazos y fases de ejecución pueden estar propiciadas por coyunturas distintas y cambiantes, lo más operativo es realizar un diseño modular de cada una de las diferentes actuaciones, de modo tal que sea posible, bien llevar a cabo simultáneamente todos los ejes de actividad aunque asumiendo sólo una parte del volumen que conlleva cada una de las actuaciones o bien abordar cada una de las acciones de forma sucesiva.

Independientemente del modelo que mejor se ajuste a las circunstancias de partida, es conveniente realizar una priorización de actividades de cara a evitar obstáculos y enredos que colapsen el desarrollo general del trabajo (C.E.P., 1991) A la hora de efectuar esta priorización se deberán tener en cuenta los siguientes aspectos:

\footnotetext{
28 Al igual que las actuaciones patrimoniales, estas acciones se han concretado en algunos de sus extremos. Sin embargo, tanto el tema fundamental del texto como los problemas de espacio nos llevan a enunciar únicamente su contenido.
}

1) Planificar las primeras actividades en función de la obtención del mayor efecto con la minima inversión de esfuerzo.

2) Evitar como prioritarias aquellas acciones para cuya consecución sea necesario un largo proceso de trabajo: aquellas que implican una fase muy larga de ejecución o requieren de una gran inversión de trabajo o estudios previos.

3) Evitar también aquellas cuya necesidad está más supeditada a una afluencia masiva de visitas que a cuestiones directamente patrimoniales, por ejemplo, la creación de infraestructuras o servicios de uso masivo parece lógico que sean posteriores a la realización de actividades que atraigan visitas.

En función de estas circunstancias, las actuaciones propuestas en el proyecto para la rentabilización arqueológica del ayuntamiento de Toques fueron distribuidas en actuaciones que se podrian abordar de forma inmediata, a medio plazo y a largo plazo.

Con la organización de las diferentes actuaciones podemos dar por finalizado el trabajo de proyección. Con él prentendimos dar respuesta a la cuestión que alentó la realización de este articulo. Asi, aunque de antemano sabemos que la distancia entre un diseño y su plasmación práctica se encuentra cruzada por más circunstancias y problemáticas que las que aqui se han considerado, quisimos abordar temáticas y problemas de carácter general que nos permitiesen definir, no soluciones a dificultades concretas que van a depender de cada caso de trabajo sino, más bien, posiciones desde las que abordar las respuestas a estos problemas utilizando como marco una línea de investigación como es la ArPa.

\section{BIBLIOGRAFIA}

AYOZA IZQUIERDO, R. y ROLLO GUILLÉN, J. I. (1990): «Los parques culturales con arte rupestre en Aragón un proyecto de futuro", en VVAA.: Jornadas sobre parques con arte rupestre, Zaragoza, 201-214.

BARRERO RODRIGUEZ, C. (1990): La ordenación jurídica del Patrimonio Histórico, Madrid.

BOYER, M. (1993): "Turismo cultural y patrimonio edificado: ambigüedad de las palabras, fuerza de las imágenes", en NEYERET, R. (dir.): El patrimonio factor de desarrollo, «Col. Transversales», Lyon, 49-54. 
Burillo Mozota, F.; IBÃ̃̇lz GonzAllez, E. J,; LoZano Tena, M. V. y Andrés, M. (1992); Parque cultural de Molinos, Teruel.

BUrRILlo MOZOTA, F.; IBÁÑEz GonzÁl.ez, E. J. y Polo Cutando, C. (1994): "El Patrimonio Arqueológico en el medio rural", en VVAA.: Conservación arqueológica. Reflexión y debate sobre teoria y práctica, "Cuadernos del Instituto Andaluz del Patrimonio Históricom, III, Consejeria de Cultura, Sevilla, 36-49.

BRAUDillard, J. (1993): La ilusión del fin, Barcelona.

Cánovas, I. (1993): Turismo rural, «Col. Temas ambientales», Centro Nacional de Educación Ambiental (CNEAM-ICONA), Segovia, 1-14.

Carrera Ramirez, F. y BARBI Alonso, V. (1992): "Criterios de selección para yacimientos arqueológicos susceptibles de ser conservados», en VVAA.: Coloquio Galego de Museos, Xunta de Galicia, Santiago.

Carrera Ramirez, F.; Costas Goberna, F.; De LA Peña Santos A. y Rey Garcia, J. M. (1994): «El arte rupestre galaico. Una reflexión critica para el presente y una propuesta para el futuron, TP. 41-54.

C.E.P. (Centro Europeu del Patrimoni) (1991): Manual del II curso básico post-universitario de formación en Patrimonio, Barcelona.

Cerqueiro LANDiN, D. (1992): «Industrias líticas un pasado difuson, en CRIADO et alii: Arqueología del paisaje el área Bocelo-Furelos entre los tiempos paleoliticos y medievales. (Campañas de 1987. 1988 y 1989), "ArqueoloxiaInvestigación 6», Santiago de Compostela, 97. 128.

C.C.E. (Comisión de las Comunidades Europeas) (1994): Las acciones comunitarias que afectan al turismo (Decisión del Consejo 92/421/CEE). (COM 94; 74 final). Luxemburgo.

CRIADO BOADO, F. (1988): «Arqueologia del Paisaje y espacio megalitico en Galicia», Arqueologia espacial, 13, Teruel, 61-117.

- (1993): «Visibilidad e interpretación del registro arqueológico», TP 50, 11-37.

- (1994): «Límites y posibilidades de la arqueología del paisaje», Spal 2 (en prensa).

Criado Boado, F.; Bonilla Rodríguez, A.; CerQuiero Landin, D.; Infante Roura, F.; GonZÁlez MÉndez, M.; MÉndez FERnÁndez, F.; Penedo Romero, R.; Rodriguez Puentes, E.; Vaquero Lastres, J. y VAzQuez diaz, M. (1991): La arqueologia del paisaje en Galicia. El área Bocelo-Furelos entre los tiempos paleoliticos y medievales. (Campañas de 1987, 1988 y 1989), «Arqueoloxia-Investigación 6», Santiago de Compostela.

Criado BoAdo, F. y Gonzál.z MÉndez, M. (1994): «La puesta en valor del patrimonio arqueológico desde la perspectiva de la Arqueología del Paisaje», en VVAA.: Conservación arqueológica. Reflexión y debate sobre teoria y práctica, "Cuadernos del Instituto Andaluz del Patrimonio Histórico Il», Sevilla, 58-75.

Ferreira Priegue, E. (1988): Los caminos medievales de Galicia, "Boletin Auriense», Anexo 9. Orense.

FERnÁndez Posse de Arnálz, M. D. (1995): «El parque arqueológico de las Médulas. Proyecto y perspectivas», Seminario impartido en el curso Conservación del Patrimonio Arqueológico (2730 junio), Pontevedra.

García Blanco, A. y Caballero Zoreda, L. (1992): «La comunicación del parque arqueológico", en Jornadas internacionales arqueologia de intervención. Centro del Patrimonio Cultural Vasco.

GIMÉNEZ dE AZCÁRATE CORNIDE, R.; ROMERO SUANCES, I. y MUNILLA RUMBAO, I.: «Estudio del medio físico y del patrimonio natural del ayuntamiento de Toques», trabajo inédito inscrito en el Proyecto para la Rentabilización sociocultural del patrimonio arqueológico del ayuntamiento de Toques, Dirección Xeral de Patrimonio Histórico e Documental, Conselleria de Cultura, Xunta de Galicia.

GiSBERT, J. A. (1992): «El Patrimonio Histórico como oferta añadida al desarrollo turístico de una región. Criterios de actuación. La experiencia de Denian, en Jornadas internacionales de arqueologia de intervención, Centro del Patrimonio Cultural Vasco, San Sebastián.

GonzÁlez MÉndeZ, M. (1994): «O Patrimonio Cultural na Organización da oferta turistica galega: o papel dos ayuntamientos na creación desta oferta", FEGAMP, Revista da Federación Galega de Municipios e Provincias 5, 57-63.

Gómez Vila, J. (1993): «Prospección arqueolóxica do Camiño Primitivo e da Via Romana XIX nos ayuntamientos de Toques e Melide", Boletín do centro de estudios Melidenses 8 , $5-42$.

GuIJARRO, L. (1995): "Sandalias de viento", MOPTMA, Revista del Ministerio de Obras Públicas, Transportes y Medio Ambiente 43, 5-12.

LAFUENTE, C. (1993): «Turismo que no deja huella», Conocer 127, 48-52.

LAMBRIC, G. (1992): "The importance of the cultu- 
ral heritage in a green world : towards the development of landscape integrity assessment", en MACINNES, L., y WiCKHAM-JONES, C. (ed.): All Natural Things, Oxford, 105-133.

MAFESSOLli, M. (1994): "La socialidad en la posmodernidad", en VVAA.: En torno a la posmodernidad, Barcelona, 103-110.

ProtT, L. V. (1992): «A Common Heritage: The World Heritage Convention", MACINNES, L., y Wickham-Jones, C. (ed.): All Natural Things, Oxford, 65-86.

PRENTICE, R. (1993): Tourism and heritage attractions, London.

TALLON NiETO, M. J. (1991): El marco juridico administrativo para el desarrollo de la actividad arqueológica en España. Esbozo Histórico, tra- bajo de investigación de Tercer Ciclo, Facultad de Xeografia e Historia, U.S.C. (inédito).

VVAA. (1933): Terra de Melide, Seminario de Estudios galegos (reed. 1978), Santiago de Compostela.

VVAA. (1992a): El turismo rural en el desarrollo local, Madrid.

VVAA. (1992b): Seminario de Parques Arqueológicos, I.R.C.B.C., Madrid.

VVAA. (1992c): Parque etnoarqueológico Reina Sofia, un provecto participativo y divertido, Valladolid.

WARMER BULLETIN (1995, febrero): «Evaluación de las actitudes de la sociedad ante temas ambientales", Revista de la World Resource Foundation, 44. 